\title{
Empleo manufacturero en la Región Centro de México. Una estimación por gran división
}

\section{Manufacturing labor in the Central Región of Mexico. An estimation by great division}

\author{
Yolanda Carbajal Suárez* y Leobardo de Jesús Almonte \\ Universidad Autónoma del Estado de México, México \\ Recibido el 26 de junio de 2015; aceptado el 15 de enero de 2016 \\ Disponible en Internet el 17 de mayo de 2017
}

\section{Resumen}

Se analiza a nivel de gran división de la manufactura el desempeño de la producción y sus efectos en la generación de empleo formal de la región Centro de México. Se identifican las divisiones más dinámicas de actividad de la industria manufacturera y, a partir de estimar una función de empleo con datos de panel para cada una de las nueve grandes divisiones de la manufactura, se reporta que las divisiones de actividad I. Productos alimenticios, bebidas y tabaco, II. Textiles, prendas de vestir e industria del cuero, III. Industria de la madera y productos de madera y IX. Otras industrias manufactureras presentan una alta elasticidad ingreso del empleo $(0.716,1.035,0.781$ y 0.94$)$ y que las divisiones que integran las ramas más tecnificadas, con mayores procesos de innovación y altamente exportadoras, como la división VIII. Productos metálicos, maquinaria y equipo, presentan una elasticidad menor.

(C) 2017 Universidad Nacional Autónoma de México, Facultad de Contaduría y Administración. Este es un artículo Open Access bajo la licencia CC BY-NC-ND (http://creativecommons.org/licenses/by-nc-nd/4.0/).

Palabras clave: Actividad económica; Empleo manufacturero; Elasticidad ingreso del empleo

Códigos JEL: C23; E23; L60

\section{Abstract}

In this paper, the production performance by great division and its effects on formal job generation in the central region of Mexico is analyzed. The more dynamic manufacturing divisions are identified and with

\footnotetext{
* Autor para correspondencia.

Correo electrónico: ycarbajals@uaemex.mx (Y. Carbajal Suárez).

La revisión por pares es responsabilidad de la Universidad Nacional Autónoma de México.
} 
the estimation of an employment function with panel data for each of the nine manufacturing great divisions, it is found that divisions I. Food, beverages and tobacco, II. Textiles, clothing and leather industry, III. Wood and wood products and IX Other manufacturing industries exhibit a high income elasticity of employment $(0.716,1.035,0.781$ and 0.94$)$ and that the more technical divisions, with greater innovation processes and highly exporting divisions such as division VIII. Metal products, machinery and equipment show a lower elasticity.

(C) 2017 Universidad Nacional Autónoma de México, Facultad de Contaduría y Administración. This is an open access article under the CC BY-NC-ND license (http://creativecommons.org/licenses/by-nc-nd/4.0/).

Keywords: Economic activity; Manufacturing labor; Income elasticity of employment JEL classification: C23; E23; L60

\section{Introducción}

En los años posteriores a la Gran Recesión 2008-2009, en México se hizo más evidente la dificultad de la actividad económica por reactivar sus niveles de crecimiento y de generación de empleo. Sin embargo, estos problemas no se remiten a los años recientes; la dificultad del crecimiento ya se veía desde mediados de los años ochenta, y se intensificó con el inicio del Tratado de Libre Comercio con América del Norte (TLCAN) en 1994.

Las expectativas con el inicio del TLCAN eran optimistas con relación a las bondades de la apertura. Se tenía la confianza de que con el libre comercio se fortalecerían las exportaciones y se consolidaría el aumento sostenido de largo plazo de la actividad económica, con sus efectos en el crecimiento económico del país y en el empleo. A veinte años de inicio de las operaciones del TLCAN la evidencia de los años recientes deja ver que los saldos del libre comercio no han sido los esperados en términos de crecimiento y de generación de empleos, sobre todo en el sector manufacturero. Todo indica que este sector, aun cuando está vinculado fuertemente con la dinámica exportadora, no ha logrado influir de manera relevante en el proceso de creación de empleos (Dussel Peters, 2003).

Algunos autores sugieren que este hecho puede estar asociado con una relativa alta intensidad de capital de la manufactura y una relativa baja absorción de empleo, particularmente en los sectores más modernos y productivos de la manufactura (Dussel Peters y Cárdenas, 2007), así como con los cambios que se han presentado en la estructura de los sectores productivos durante las últimas décadas, en la que el sector servicios cada vez cobra mayor relevancia en contraposición de los sectores industrial y agropecuario.

Estos elementos son importantes porque durante muchos años el sector manufacturero ha sido considerado uno de los motores del crecimiento económico de México y un sector en el que «el impacto de la apertura comercial puede ser directamente percibido, ya que ahí se concentra el mayor número de actividades relacionadas con los bienes comerciables» (De León, 2013, p. 10); sin embargo, a partir de la década de los años ochenta del siglo xx la industria manufacturera ha presentado cambios sustanciales en su estructura comercial, productiva, de inversión y de empleo (véase Alcaraz y García, 2006; Arriaga, Leyva y Estrada, 2005; De León, 2002; Flores y Capdevielle, 2003; Fujii y Cervantes, 2008; Fragoso, 2003) que no se han reflejado de manera decisiva en la generación de empleo formal. Algunos otros autores, como Mariña (2005), argumentan que el proceso de apertura no se ha reflejado en un incremento sustancial del empleo formal y mejores condiciones laborales. 
Trabajos más recientes (Quintana, Andrés-Rosales y Namkwon, 2013) explican que el desarrollo del sector manufacturero mexicano, si bien ha contribuido a la productividad de los demás sectores, no ha sido capaz de operar como fuerza de arrastre ni de generar efectos de derrama del crecimiento. Lo anterior se debe a que en México se apuesta por un modelo de crecimiento económico en el que el sector externo determina la trayectoria del crecimiento y el sector manufacturero solo lo complementa. Más aún, se ha dado evidencia de que la falta de crecimiento económico ha fortalecido una innumerable cantidad de procesos negativos para la economía mexicana, entre ellos la incapacidad para crear empleos (Sánchez, 2012).

Aunque la literatura que analiza al sector manufacturero en México es relativamente amplia, son pocos los trabajos que apuntan hacia una línea de investigación que trate de explicar con algún detalle los determinantes del empleo por gran división de la industria manufacturera a nivel de entidades federativas o de regiones. Parte importante de este esfuerzo se encuentra en los trabajos de Calderón y Martínez (2005) y de Martínez, Barajas y Ruiz (2012), quienes investigan el impacto de las externalidades en el crecimiento del empleo manufacturero, y en el de EscobarMéndez (2011), quien analiza el crecimiento del empleo manufacturero en las principales zonas metropolitanas con énfasis en el peso de los factores de localización industrial.

De manera específica, los trabajos de Livas y Krugman (1992) y de Hanson (1994) se han convertido en referentes en el análisis de los patrones de crecimiento industrial entre las regiones, sobre todo porque reportan cambios significativos en los patrones de crecimiento del empleo industrial y destacan el rápido crecimiento de la actividad manufacturera en la frontera norte y la pérdida en las grandes ciudades de México.

En este contexto, el objetivo de este trabajo es analizar, a nivel de gran división de la manufactura, el desempeño de la producción y la generación de empleo manufacturero en las entidades federativas de la región Centro de México, así como identificar algunos determinantes del empleo que pueden explicar las diferencias entre las divisiones de actividad de la manufactura.

El análisis del artículo se centra en la región Centro de México y se divide en tres apartados, además de la introducción y las conclusiones. En el primero se contextualiza el problema del escaso crecimiento de la actividad económica de México de las décadas recientes y los efectos que se han presentado de manera general en la manufactura y en el empleo; en el segundo apartado se puntualiza el análisis de la manufactura y la estructura del empleo y la producción para las entidades de la región Centro de México a nivel de gran división; finalmente, en el tercer apartado se presentan y se discuten los resultados de la estimación, con datos de panel, de las funciones de empleo para cada una de las nueve grandes divisiones de la manufactura en la región Centro de México.

\section{El lento crecimiento, la manufactura y el empleo en México}

La economía mexicana en las tres décadas recientes ha experimentado un ritmo de crecimiento menor al que tenía a principios de los años ochenta. Este desempeño se ha explicado a partir de diferentes argumentos, pero hay un punto central que merece atención y que se refiere a los efectos que el crecimiento de la actividad económica ha tenido en la generación de empleo.

Con relación a este punto, algunos autores (Calderón y Sánchez, 2012) han analizado el bajo crecimiento económico en México y la imposibilidad para generar los empleos necesarios. Específicamente dan evidencia de la alta correlación entre el bajo crecimiento económico del PIB total y el bajo crecimiento del producto manufacturero. De acuerdo con estos autores, entre 1982 y 2010 la economía mexicana creció un $2.1 \%$ anual; asociado a este fenómeno se encuentra 
el elevado desempleo y la precarización del empleo: entre 1982 y 2008 apenas se crearon 354,306 empleos en promedio anual en el sector formal de la economía.

En este sentido, parte importante de la explicación de la insuficiencia de la economía formal para generar los empleos que demanda el mercado de trabajo se encuentra en la importancia de la dinámica de la actividad económica del país. Si se revisan, en un periodo relativamente largo, las tasas de crecimiento del PIB real y del empleo total para la economía mexicana, la tendencia que se observa es que la crisis de 1982 marcó el fin de una fase de crecimiento del producto de tasas relativamente altas (6.8 promedio anual entre 1970 y 1981) y el inicio de un proceso de lento crecimiento. En el periodo 1982-2013 el crecimiento promedio del PIB real fue del $2.3 \%$, mientras que el crecimiento del empleo fue solo del $1.2 \%$ (fig. 1).

Este panorama es importante porque sugiere revisar lo que está ocurriendo con la producción sectorial, con el fin de identificar si este proceso de lento crecimiento ha permeado en magnitudes similares a los sectores de actividad económica.

En la tabla 1 se pueden ver con cierto detalle los cambios en la estructura del PIB y del empleo total y sectorial. Primero, es evidente que para todo el periodo que comprende de 1970 a 2014 el crecimiento promedio del PIB real de $3.5 \%$ no ha sido suficiente para que el empleo total crezca de manera importante (para este periodo ha crecido en promedio $1.9 \%$ al año); y destaca que el sector que más ha crecido es el de servicios, con una tasa de crecimiento promedio anual del PIB real en $3.8 \%$ y del empleo de $2.7 \%$; mientras que en la manufactura aun con un crecimiento promedio del PIB real de $3.5 \%$ el empleo solo ha crecido a una tasa promedio de $0.9 \%$, apenas arriba del sector agropecuario. Además, se debe destacar que, de acuerdo con la desviación estándar del PIB de la manufactura, es un sector con fluctuaciones importantes respecto a la media, contrario con lo que ocurre con el sector servicios; además, la manufactura es un sector muy sensible a las fluctuaciones de la economía mexicana y del sector externo, de ahí que reporte años con caídas muy fuertes y periodos de auge con tasas de crecimiento muy importantes.

Si dividimos el periodo 1970-2011 en dos subperiodos (1970-1981 y 1982-2011) para identificar los cambios en la estructura del empleo sectorial posterior a la crisis de 1982 y que se ha convertido en el punto de ruptura e inicio de un modelo de crecimiento basado en la demanda

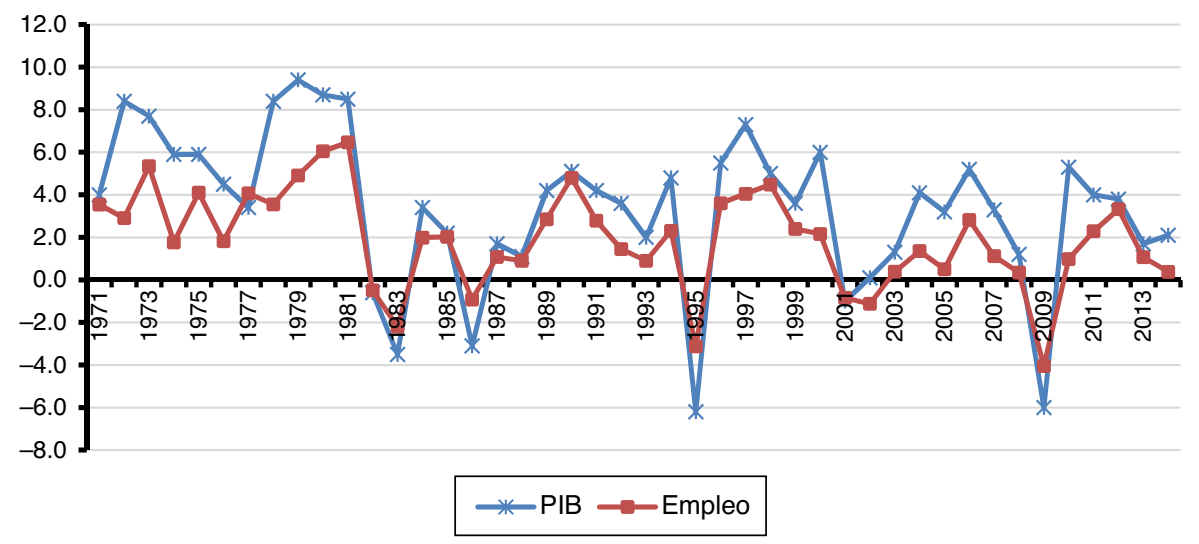

Figura 1. México: producto interno bruto real y empleo total, 1971-2014. Tasas de crecimiento.

Fuente: elaborado con datos del Sistema de Cuentas Nacionales de México (INEGI, 2014a) y de la Encuesta Nacional de Ocupación y Empleo (INEGI, 2014b). 
Tabla 1

México: tasa de crecimiento del PIB real y del empleo, total y sectorial. Estadísticas básicas por periodos, 1970-2011

\begin{tabular}{|c|c|c|c|c|c|c|c|c|}
\hline \multirow[t]{2}{*}{ Sectores } & \multicolumn{2}{|l|}{ Total } & \multicolumn{2}{|l|}{ Agropecuario } & \multicolumn{2}{|c|}{ Manufactura } & \multicolumn{2}{|l|}{ Servicios } \\
\hline & PIB & Empleo & PIB & Empleo & PIB & Empleo & PIB & Empleo \\
\hline & & & & $1970-2011$ & & & & \\
\hline Media & 3.50 & 1.90 & 2.10 & 0.30 & 3.50 & 0.90 & 3.80 & 2.70 \\
\hline Máximo & 9.40 & 6.50 & 8.00 & 9.20 & 10.50 & 8.80 & 10.20 & 7.00 \\
\hline Mínimo & -6.20 & -4.00 & -3.40 & -4.80 & -9.90 & -10.60 & -5.90 & -1.40 \\
\hline Desv. est. & 3.70 & 2.30 & 3.00 & 3.10 & 5.10 & 4.30 & 3.50 & 2.00 \\
\hline Jarque-Bera & $5.0(0.07)$ & $1.04(0.59)$ & $0.409(0.81)$ & $\begin{array}{c}0.87(0.64) \\
1970-1981\end{array}$ & $4.89(0.08)$ & $2.33(0.31)$ & $4.1(0.13)$ & $0.86(0.64)$ \\
\hline Media & 6.80 & 4.00 & 3.90 & 1.57 & 6.30 & 3.60 & 7.20 & 5.10 \\
\hline Máximo & 9.40 & 6.50 & 8.00 & 9.20 & 10.20 & 7.50 & 10.20 & 7.00 \\
\hline Mínimo & 3.40 & 1.80 & -2.20 & 4.80 & 2.90 & 0.20 & 3.60 & 3.80 \\
\hline Dev. est. & 2.10 & 1.60 & 3.30 & 4.20 & 2.70 & 2.20 & 2.10 & 1.00 \\
\hline Jarque-Bera & $1.1(0.56)$ & $0.44(0.80)$ & $0.69(0.70)$ & $\begin{array}{c}0.39(0.82) \\
1982-2011\end{array}$ & $1.00(0.60)$ & $0.16(0.92)$ & $0.7(0.71)$ & $0.72(0.69)$ \\
\hline Media & 2.20 & 1.20 & 1.40 & -0.10 & 2.40 & -0.10 & 2.50 & 1.80 \\
\hline Máximo & 7.30 & 4.80 & 6.30 & 4.60 & 10.50 & 8.80 & 6.20 & 4.80 \\
\hline Mínimo & -6.20 & -4.00 & -3.40 & -4.40 & -9.90 & -10.60 & -5.90 & -1.40 \\
\hline Dev. est. & 3.40 & 2.10 & 2.60 & 4.50 & 5.40 & 4.40 & 3.00 & 1.50 \\
\hline Jarque-Bera & $5.7(0.05)$ & $1.54(0.46)$ & $1.21(0.54)$ & $\begin{array}{c}1.35(0.50) \\
2001-2011\end{array}$ & $1.92(0.38)$ & $0.42(0.81)$ & $8.6(0.01)$ & $0.26(0.87)$ \\
\hline Media & 1.90 & 0.30 & 1.20 & -0.80 & 1.20 & -2.60 & 2.50 & 1.30 \\
\hline Máximo & 5.30 & 2.80 & 6.30 & 2.60 & 9.90 & 1.60 & 5.30 & 2.90 \\
\hline Mínimo & -6.00 & -4.00 & -3.20 & -4.40 & -9.90 & -10.60 & -4.90 & -1.40 \\
\hline Dev. est. & 3.30 & 1.80 & 3.00 & 2.70 & 5.40 & 3.80 & 3.10 & 1.20 \\
\hline Jarque-Bera & $2.9(0.22)$ & $2.39(0.30)$ & $0.43(0.8)$ & $1.19(0.55)$ & $0.37(0.83)$ & $1.16(0.55)$ & $3.2(0.20)$ & $156(0.45)$ \\
\hline
\end{tabular}

Fuente: elaborado con datos del Sistema de Cuentas Nacionales (INEGI, 2014a, 2014b).

externa y que ha dado paso a la fase de lento crecimiento de México, encontramos algunas regularidades importantes de manera agregada.

Es claro que entre 1970 y 1981 se vivió la fase final del milagro mexicano con tasas de crecimiento de la economía mexicana relativamente altas - para el PIB total del 6.8\% promedio anual y para el empleo total del $4.0 \%$ anual-y con un sector manufacturero también dinámico, con crecimiento del PIB del $6.3 \%$ promedio anual (con algunos años con tasas de crecimiento del PIB real de $10.2 \%$ ) y del empleo del $3.6 \%$ promedio por año. Este periodo, relativamente dinámico para los tres sectores de producción, cambió de manera importante a principios de los ochenta del siglo pasado (tabla 1).

Para el periodo 1982-2011 la manufactura dejó de crecer a las tasas que la caracterizaron hasta antes de la crisis de 1982 y ha seguido una tendencia similar al comportamiento de la economía mexicana, con una tasa promedio del $2.4 \%$, aunque con una tasa de crecimiento del empleo negativa, del $-0.1 \%$.

El escenario se complica si analizamos el periodo 2001-2011, en el que el crecimiento promedio de la manufactura no solo ha sido menor (1.2\%), sino que el empleo en promedio presentó tasas de crecimiento negativas del $-2.6 \%$, incluso menores a las del sector agropecuario, que es un expulsor neto de trabajo (tabla 1). Esta disminución en el crecimiento de la actividad manufacturera se puede explicar porque desde el año 2000 el comercio exterior de México no volvió a experimentar el 


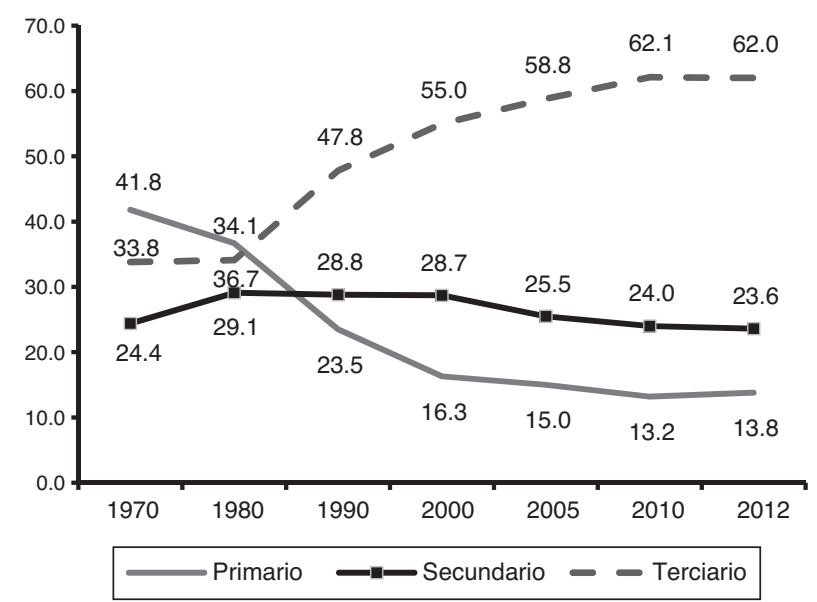

Figura 2. México: estructura porcentual del empleo sectorial, 1970-2012.

Fuente: elaborado con datos del Censo General de Población y Vivienda (INEGI, 1970, 1980, 1990, 2000, 2010) y de la Encuesta Nacional de Ocupación y Empleo (INEGI, 2005, 2014b).

dinamismo de los años de 1993 a 2000, particularmente debido a la competencia con China y a la creciente desintegración del TLCAN (Dussel Peters y Ortiz, 2012).

En este sentido, Dussel Peters (2003) señala que la capacidad de generación de empleos de la manufactura se ha visto reducida drásticamente, pues el crecimiento promedio del empleo en estos años ha sido negativo, lo que deja ver que el sector ha expulsado trabajo, lo que evidencia la disminución en su capacidad de arrastre de la actividad económica del país. Por otro lado, también argumenta que quizá los resultados se puedan explicar por el hecho de que a partir de 1988 la manufactura se ha especializado en actividades exportadoras e intensivas en capital, lo que ha generado un reducido proceso de generación de empleo.

Por otro lado, Dussel Peters y Ortiz (2013) destacan una caída sistemática del peso relativo del empleo manufacturero permanente con respecto al empleo permanente total, del $35.6 \%$ en 2000 al $26.1 \%$ en octubre de 2012. Más aún, señalan que el empleo manufacturero resultó uno de los más afectados por la crisis económica de 2008, pues de los 701,000 empleos permanentes perdidos entre octubre de 2008 y mayo de 2009, 349,000 correspondieron a empleo manufacturero, lo que significa que uno de cada dos empleos permanentes perdidos entre esos meses se situaba en las actividades manufactureras, lo cual se tradujo en una caída del 9.2\% en los ritmos de expansión del empleo manufacturero permanente.

Otro de los cambios fundamentales, con esta disminución importante en la generación de empleos del sector manufacturero, es la continua expansión del sector servicios, tanto por su peso relativo en la economía como por su estratégico papel en el funcionamiento de los sistemas productivos (Chávez y Zepeda, 1996). Así, la estructura laboral por sector de actividad se ha transformado de manera importante durante las últimas décadas, y el sector servicios cada vez cobra mayor importancia en contraposición con los sectores industrial y agropecuario. En la figura 2 se observa el incremento significativo en el empleo del sector servicios, mientras que la manufactura a partir de la crisis de 1982 ha dejado de crecer a los niveles previos; incluso es evidente una caída persistente en los niveles de empleo de este sector a partir de 2000 , y más aguda aún a partir de 2008 . 
Esta recomposición de la estructura del empleo sectorial es relevante desde diferentes perspectivas; primero, porque la manufactura «es importante para absorber a trabajadores con poca capacitación, por ser un sector donde toma forma y crece la clase media del mundo» (ONUDI, 2013); es considerada una actividad con características únicas: sus encadenamientos hacia atrás y hacia delante, su potencial en la generación de valor agregado, de difusión tecnológica, de crecimiento de la productividad y, desde luego, como generadora de empleo formal (Dussel Peters, 1997). Además, generalmente brinda al trabajador mayores beneficios y seguridad que los empleos en otros sectores y tiende a desarrollar mejores habilidades que trabajos equivalentes en el resto de la economía (Lavopa y Szirmai, 2012, citados en ONUDI, 2013).

Gracias al dinamismo que posee la manufactura, sus efectos se transmiten hacia otros sectores de actividad, induciendo conductas innovadoras en los agentes económicos (Garduño, 2009). Caso contrario representa el sector servicios, sobre todo porque incorpora parte importante del empleo informal.

Sobre este punto, Dussel Peters y Ortiz (2013) señalan que desde el año 2000 el empleo se ha reorientado de la industria a los servicios, y que la manufactura ha perdido 9.5 puntos porcentuales en la generación de empleos entre 2000 y noviembre de 2013, mientras los servicios a empresas y personas han elevado su participación porcentual en poco más del 5.0\%. En esta recomposición, el empleo agrícola sigue la tendencia que lo ha caracterizado en las últimas décadas: la de un sector cada vez con menor dinámica en la generación de empleos y expulsor de mano de obra.

Para el caso de las regiones de México, Sánchez (2011) analiza el estancamiento económico que prevalece en México desde 1982 y demuestra, en el marco del análisis kaldoriano, que la insuficiente dinámica del sector manufacturero es la causa principal de las bajas tasas de crecimiento económico y empleo en las regiones de México y en el país en general. Específicamente, destaca la existencia de un círculo vicioso entre el bajo crecimiento de la producción y el bajo crecimiento del empleo (que conlleva bajos ingresos y, por tanto, escaso crecimiento del mercado), con lo que se perpetúa el círculo vicioso de estancamiento económico.

Evidentemente las regiones de México no son ajenas a esta tendencia, sobre todo porque la actividad productiva no ha respondido con claridad a la presión que la población económicamente activa ejerce sobre el mercado de trabajo, y porque ciertamente la manufactura, como sector más dinámico cada vez genera menos empleos. En este contexto, en el siguiente apartado se aborda, de manera específica, el caso de la región Centro de México.

\section{La estructura del empleo y la producción de la manufactura por gran división en la región Centro de México}

Como se ha anotado, se aborda específicamente el caso de la región Centro de México, integrada por el Distrito Federal, el Estado de México, Querétaro, Puebla, Hidalgo, Morelos y Tlaxcala (fig. 3), entidades que, además de la ubicación geográfica, tienen como punto coincidente la presencia de la industria manufacturera como una de las principales actividades económicas y de generación de empleo.

El Distrito Federal y el Estado de México simbolizan la cuna del proceso de industrialización en México, y si bien en años recientes han presentado un proceso de «desindustrialización», en el sentido de que las tasas de crecimiento de las actividades industriales se han visto disminuidas comparadas con las que se tenían en años anteriores, prevalecen como dos de las entidades más representativas a nivel nacional. En 2012 su aportación al PIB total nacional fue del 26.2\% y al manufacturero del $20.4 \%$ (INEGI, 2014c), además de que son los estados más poblados del país y en suma concentran 24 millones de personas (el 21.4\% del total nacional) (INEGI, 2010). 


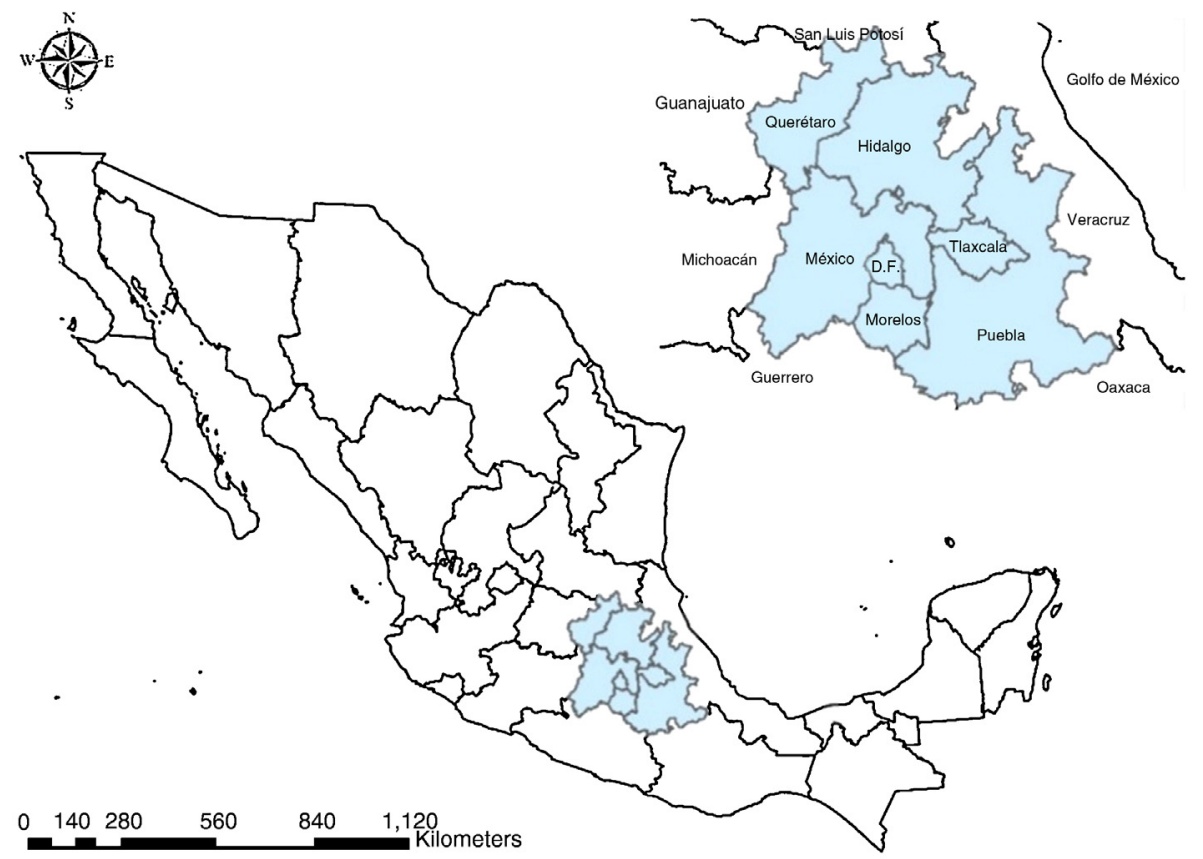

Figura 3. Región Centro de México

Fuente: elaborado con ArcMap (10.1).

En los otros estados, las actividades manufactureras - aun cuando en los años recientes han perdido representatividad con relación a las actividades del sector secundario- tienen una importante participación dentro de la estructura productiva estatal. Las aportaciones de estas actividades al PIB total de cada estado son Querétaro 28.7\%, Puebla 24.4\%, Hidalgo 33.4\%, Morelos $24.3 \%$ y Tlaxcala $29.7 \%$ (INEGI, 2014c).

Si bien el peso de la industria manufacturera se ha reducido con relación al sector servicios, es indiscutible que continúa como un sector cuya actividad es muy importante para impulsar la actividad económica agregada de las regiones y del país y, en consecuencia, el empleo. Algunos autores que han analizado los encadenamientos productivos «hacia atrás» de la manufactura dan evidencia de su capacidad de arrastre y reportan una capacidad de arrastre directa y total de 1.63 veces, por arriba del sector terciario (1.36 veces) y de las actividades primarias (1.31 veces). Es decir, la evolución de la economía mexicana depende significativamente del desempeño de su industria manufacturera (véase Guerrero de Lizardi, 2012).

En este sentido, es importante analizar el desempeño que ha mostrado la industria manufacturera para identificar las divisiones de actividad más dinámicas en cada una de las entidades federativas de la región Centro ${ }^{1}$.

\footnotetext{
${ }^{1}$ La industria manufacturera se divide en 9 grandes divisiones: División I. Productos alimenticios, bebidas y tabaco; División II. Textiles, prendas de vestir e industria del cuero; División III. Industria de la madera y productos de madera; División IV. Papel, productos de papel, imprentas y editoriales; División V. Sustancias químicas; derivados del petróleo; productos de caucho y plásticos; División VI. Productos de minerales no metálicos, exceptuando derivados del petróleo y carbón; División VII. Industrias metálicas básicas; División VIII. Productos metálicos, maquinaria y equipo; División IX. Otras industrias manufactureras.
} 


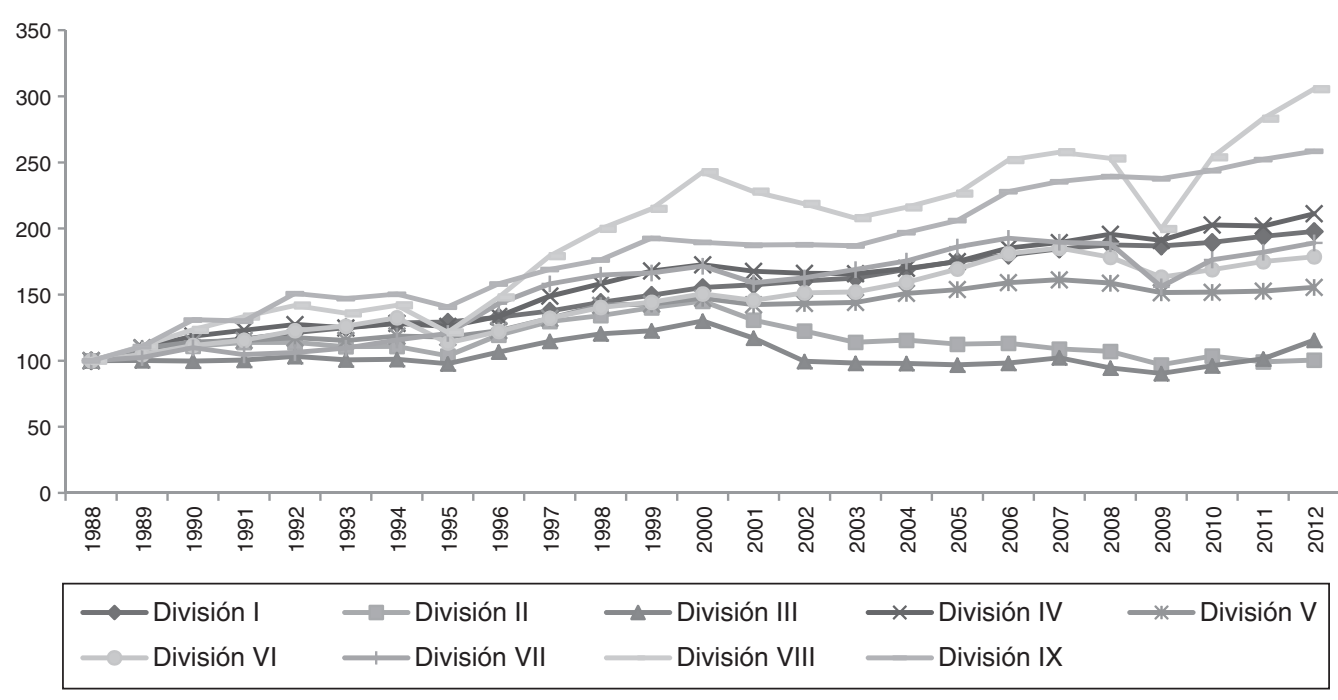

Figura 4. México: evolución del PIB de la manufactura por gran división, 1988-2012.

Índice $1988=100$, a precios constantes de 2003.

Fuente: elaborado con datos de la Encuesta industrial mensual (INEGI, 1994b, 2012).

De acuerdo con el indicador de la evolución de la producción de la manufactura por gran división, su desempeño en los años recientes no ha sido homogéneo. Las divisiones II y III prácticamente se han estancado, sobre todo a partir del año 2000, mientras las divisiones VIII y IX se han destacado porque posterior a la crisis de 1995 su evolución ha estado por arriba del resto de las divisiones de la manufactura (fig. 4).

Aunque el dinamismo de las diferentes divisiones de la manufactura no es el mismo, en la mayoría se observa un proceso de crecimiento; sin embargo, esta tendencia contrasta con la que se observa en el empleo. Particularmente, después del año 2000 los niveles de empleo han disminuido para todas las divisiones, lo que deja ver un proceso de crecimiento sin efectos consecuentes en los volúmenes de empleo, incluso la tendencia decreciente de los últimos años supondría una pérdida de empleos formales (fig. 5).

Para el caso de la región Centro, esta tendencia no ha cambiado de manera importante. En específico, algunos autores reportan que la región ha perdido representatividad en el conjunto de la actividad económica, mientras otras regiones (sobre todo las del norte) han ganado participación. Sánchez (2011) refiere que entre 1993 y 2010 la tasa de crecimiento promedio anual de las manufacturas fue del $2.68 \%$ en todo el país. En la región Centro Norte fue del $5.54 \%$; en la Frontera Norte, del 4.11\%; en la Pacífico, del 1.71\%; en la Sur, del 1.70\%; en la Golfo, del 1.54\%; en la Occidente, del $1.43 \%$, y en la Centro, de solo el 1.35\%. Esta última región, como lo refiere Sánchez (2011, p. 104), «después de ser el núcleo industrial del país paulatinamente ha dejado de serlo. En los últimos años se ha dado un claro desplazamiento de las actividades manufactureras a favor de las regiones del norte del país». Más aún, «[...] se encuentra en franco declive, en solo cuatro años logró presentar un crecimiento por encima de 5\% y en 2009 fue la región más seriamente afectada por la crisis al descender su producción anual 8.5 por ciento» (Sánchez, 2011, p. 107).

Calderón y Martínez (2005) concluyen que el análisis de la distribución del empleo por regiones revela que a partir del proceso de apertura comercial la región Norte ha tenido una 


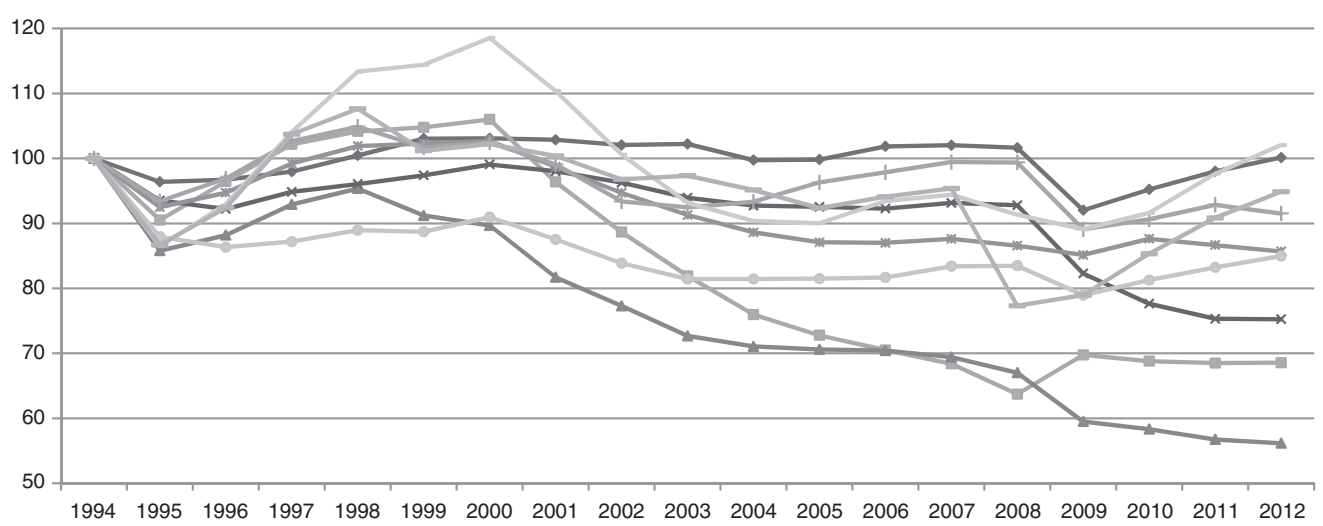

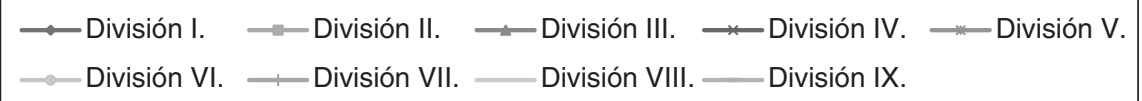

Figura 5. México: evolución del empleo de la manufactura por gran división, 1994-2012.

Índice $1994=100$

Fuente: elaborado con datos la Encuesta industrial mensual (INEGI, 1994b, 2012).

participación creciente, mientras que la región Centro muestra una baja muy significativa del empleo manufacturero, las remuneraciones y el valor agregado de esta industria.

Si bien la evidencia que se presenta para la manufactura deja ver heterogeneidades en el crecimiento por regiones, también es importante analizar lo que ocurre por división de actividad, sobre todo porque las nueve grandes divisiones que integran a la manufactura no son homogéneas en su estructura y responden de forma diferenciada a los vaivenes de la economía mundial.

A partir de información censal de los años 1985, 1988, 1993, 1998, 2003 y 2008 (INEGI, varios años) se pueden observar algunas regularidades a nivel de división de actividad de la manufactura para dos periodos: 1985-1993 y 1993-2008.

De manera general, la Centro es una región en la que el crecimiento de la actividad económica, medida a partir del valor agregado censal bruto real (VACBR), es bajo e incluso negativo en algunas divisiones de actividad y los cambios que se presentan entre los dos periodos no son significativos por su magnitud. Pero destacan algunas entidades federativas por la dinámica, o las caídas importantes, que presentan algunas divisiones de actividad (tabla 2), como se expone a continuación.

En el caso de la División I. Productos alimenticios, bebidas y tabaco, la región en su conjunto presenta una disminución en el crecimiento promedio anual del VACBR (del $2.16 \%$ entre el periodo 1985-1993 al 1.77\% para el periodo 1993-2008), aunque destacan por su crecimiento los estados de Hidalgo, Puebla, Querétaro y Tlaxcala; sobre todo Hidalgo, que en los dos periodos ha crecido a tasas del 8.0 y del 7.5\% promedio anual. La particularidad de Puebla, Querétaro y Tlaxcala es que de un periodo a otro crecieron de manera importante, incluso hasta siete veces más, como es el caso de Tlaxcala. El Estado de México ha mantenido prácticamente los niveles de crecimiento (tabla 2).

Para la División II. Textiles, prendas de vestir e industria del cuero el periodo 1993-2008 significó una fase de recuperación, en el sentido de que en el total de la región entre los años 1985 y 1993 esta división presentó tasas medias de crecimiento negativas. Sin embargo, destacan los casos de Hidalgo, que de registrar caídas en la producción cercanas al 9.0\% entre 1985 y 
Tabla 2

Región Centro: valor agregado censal bruto real y empleo. Crecimiento promedio anual por periodos, 1985-2008. A precios constantes de 2004

\begin{tabular}{|c|c|c|c|c|c|c|c|c|c|c|c|c|}
\hline \multirow{2}{*}{$\begin{array}{l}\text { Periodo } \\
\text { Entidad }\end{array}$} & \multicolumn{2}{|c|}{$1985-1993$} & \multicolumn{2}{|c|}{$1993-2008$} & \multicolumn{2}{|c|}{$1985-1993$} & \multicolumn{2}{|c|}{$1993-2008$} & \multicolumn{2}{|c|}{$1985-1993$} & \multicolumn{2}{|c|}{ 1993-2008 } \\
\hline & VACBR & $\overline{\text { Empleo }}$ & VACBR & $\overline{\text { Empleo }}$ & VACBR & $\overline{\text { Empleo }}$ & VACBR & $\overline{\text { Empleo }}$ & VACBR & $\overline{\text { Empleo }}$ & VACBR & $\overline{\text { Empleo }}$ \\
\hline & \multicolumn{4}{|c|}{ División I } & \multicolumn{4}{|c|}{ División II } & \multicolumn{4}{|c|}{ División III } \\
\hline $\begin{array}{l}\text { Distrito } \\
\text { Federal }\end{array}$ & 1.90 & -0.05 & -0.47 & 0.23 & -1.45 & -0.49 & -1.25 & 0.16 & -1.01 & -1.34 & -1.47 & -0.87 \\
\hline Hidalgo & 8.00 & 5.61 & 7.54 & 5.58 & -8.89 & 6.67 & 2.12 & 7.59 & 1.37 & 7.29 & 3.16 & 6.71 \\
\hline México & 2.49 & 3.28 & 2.81 & 3.87 & -1.53 & 1.17 & 0.26 & 3.45 & -0.93 & -0.57 & 0.52 & 3.80 \\
\hline Morelos & 5.11 & 0.83 & 0.85 & 1.80 & 0.33 & 4.88 & 3.58 & 4.95 & 2.74 & 4.65 & 7.99 & 10.05 \\
\hline Puebla & 1.50 & 3.91 & 4.04 & 2.87 & -2.18 & 3.78 & 3.42 & 6.90 & 7.21 & 12.36 & 7.90 & 7.85 \\
\hline Querétaro & 0.96 & 3.57 & 5.57 & 2.95 & 1.40 & 4.86 & 3.90 & 7.31 & 20.57 & 6.55 & 4.52 & 6.16 \\
\hline Tlaxcala & 1.03 & 4.23 & 7.40 & 6.53 & -6.07 & 1.11 & 3.51 & 5.63 & 4.21 & 3.48 & 8.20 & 7.56 \\
\hline \multirow[t]{2}{*}{ Total } & 2.16 & 1.85 & 1.77 & 2.17 & -2.20 & 1.56 & 0.80 & 3.83 & -0.39 & 0.87 & 0.35 & 2.59 \\
\hline & \multicolumn{4}{|c|}{ División IV } & \multicolumn{4}{|c|}{ División V } & \multicolumn{4}{|c|}{ División VI } \\
\hline $\begin{array}{l}\text { Distrito } \\
\text { Federal }\end{array}$ & 4.53 & 2.47 & 1.25 & 1.45 & -3.67 & -1.40 & -1.63 & 0.98 & -7.79 & -3.80 & -11.88 & -1.98 \\
\hline Hidalgo & 6.85 & 9.83 & 7.22 & 9.42 & -0.86 & 1.63 & -5.91 & 1.50 & -6.32 & -1.55 & 4.90 & 0.04 \\
\hline México & -1.21 & 2.08 & -1.47 & 1.88 & -0.90 & 1.37 & 1.55 & 0.96 & -1.12 & 0.71 & -0.34 & 0.12 \\
\hline Morelos & -5.73 & 1.34 & -2.26 & 4.96 & 1.54 & 2.49 & 3.04 & 0.40 & 2.92 & 3.08 & 7.67 & 2.88 \\
\hline Puebla & -1.99 & 5.25 & 2.21 & 3.60 & -4.27 & 2.75 & 1.91 & 2.74 & -2.86 & 6.77 & 7.78 & 4.30 \\
\hline Querétaro & 2.03 & 7.01 & 8.73 & 5.19 & -4.99 & 0.45 & 4.75 & 4.92 & -8.27 & 1.50 & 2.80 & 1.14 \\
\hline Tlaxcala & 9.24 & 1.93 & 14.25 & 7.57 & -0.15 & 8.63 & -1.97 & 3.47 & 10.20 & 4.03 & 12.76 & 9.57 \\
\hline \multirow[t]{2}{*}{ Total } & 2.36 & 2.65 & 0.85 & 1.93 & -2.50 & 0.12 & 0.05 & 1.22 & -3.37 & 0.98 & 1.38 & 1.25 \\
\hline & \multicolumn{4}{|c|}{ División VII } & \multicolumn{4}{|c|}{ División VIII } & \multicolumn{4}{|c|}{ División IX } \\
\hline $\begin{array}{l}\text { Distrito } \\
\text { Federal }\end{array}$ & -7.42 & -8.63 & -8.99 & -9.41 & -0.94 & -1.83 & -8.24 & -1.37 & 3.90 & 1.43 & -1.95 & 0.42 \\
\hline Hidalgo & -37.53 & -16.35 & -0.09 & 7.25 & -8.04 & -2.12 & -3.21 & -1.59 & 34.99 & 20.98 & 7.61 & 12.07 \\
\hline México & 9.90 & 16.81 & -5.76 & -4.73 & -0.82 & -0.58 & 1.33 & 0.74 & -6.06 & 1.04 & 3.69 & 3.05 \\
\hline Morelos & -58.08 & nd & nd & nd & 5.94 & 4.05 & -8.89 & 1.02 & 11.77 & 17.48 & 2.42 & 5.55 \\
\hline Puebla & 80.36 & -5.20 & -4.20 & -6.00 & -9.01 & 1.95 & 4.91 & 4.07 & 32.41 & 22.27 & 21.70 & 16.14 \\
\hline Querétaro & -27.43 & -2.30 & 4.80 & -10.48 & -3.90 & 1.23 & 4.10 & 3.47 & 6.00 & 8.39 & 5.97 & 7.44 \\
\hline Tlaxcala & -1.19 & -8.78 & -1.47 & -5.81 & -2.28 & -1.18 & 8.23 & 4.49 & 38.73 & 36.06 & 4.88 & 6.75 \\
\hline Total & -2.68 & -0.21 & -6.11 & -5.94 & -1.73 & -0.67 & -0.84 & 0.56 & -0.18 & 2.53 & 0.86 & 2.11 \\
\hline
\end{tabular}

División I. Productos alimenticios, bebidas y tabaco; División II. Textiles, prendas de vestir e industria del cuero; División III. Industria de la madera y productos de madera; División IV. Papel, productos de papel, imprentas y editoriales; División V. Sustancias químicas; derivados del petróleo; productos de caucho y plásticos; División VI. Productos de minerales no metálicos, exceptuando derivados del petróleo y carbón; División VII. Industrias metálicas básicas; División VIII. Productos metálicos, maquinaria y equipo; División IX. Otras industrias manufactureras.

Fuente: elaborado con datos de los Censos económicos 1985, 1988, 1993, 1998, 2003 y 2008 (INEGI, 1986, 1989, 1994a, 1999, 2004, 2009).

1993 para los años 1993-2008, ya crecía a tasas del 2.12\% anual; o de Tlaxcala, que para los mismos periodos crecía en promedio -6.07 y $3.51 \%$. Es importante mencionar el proceso de consolidación de Querétaro, que paulatinamente ha presentado crecimientos consistentes en esta división de actividad (tabla 2).

La División III. Industria de la madera y productos de madera es de relativa fortaleza para algunas entidades de la región, específicamente Morelos, Puebla y Tlaxcala. Entre los dos periodos de análisis se registra un crecimiento importante en la actividad económica de esta división de actividad (tabla 2), que contrasta con el relativo estancamiento de la evolución de esta división para el total de la economía mexicana (fig. 4).

En el caso de la División IV. Papel, productos de papel, imprentas y editoriales se observa un proceso de desaceleración del Distrito Federal en el crecimiento de esta actividad y un crecimiento importante de Hidalgo, Querétaro y Tlaxcala (7.2, 8.7 y 14.25\%, respectivamente, para el periodo 
1993-2008), además de las dificultades del Estado de México y de Morelos para reactivar el crecimiento en esta actividad. En el caso de Puebla se registra una recuperación para los años posteriores a 1993 (tabla 2).

La División V. Sustancias químicas; derivados del petróleo; productos de caucho y plásticos es una división en la que se han dado procesos de recuperación importantes en los estados de México, Morelos, Puebla y Querétaro; sin embargo, también se ha intensificado la caída en el crecimiento en el resto de las entidades federativas que integran la región Centro, de manera más intensa en el estado de Hidalgo (tabla 2).

Para la División VI. Productos de minerales no metálicos, exceptuando derivados del petróleo y carbón se observan tasas de crecimiento relativamente altas para la mayoría de las entidades de la región en el periodo 1993-2008. Destaca el caso de Tlaxcala, cuyo crecimiento de la producción alcanza tasas promedio del $12.7 \%$, y el Distrito Federal y el Estado de México, que registran tasas negativas del 11.8 y del $0.34 \%$, respectivamente (tabla 2 ).

De acuerdo con la información, parece que la División VII. Industrias metálicas básicas ha sido de las que han perdido en este proceso de globalización, al menos en la región Centro. Las tasas promedio de crecimiento que se registran para las entidades federativas son negativas en los dos periodos, a excepción de Querétaro, que reporta un crecimiento importante entre 1993 y 2008 (tabla 2).

El caso de la División VIII. Productos metálicos, maquinaria y equipo merece especial atención, sobre todo porque es una de las divisiones de actividad con mayores posibilidades de generar dinámicas de expansión de la producción y de mayor valor agregado porque, entre otras, incluye al sector automotriz, que se ha convertido en un referente en los procesos de innovación y crecimiento de la producción. En esta división de actividad sobresalen los estados de México, Puebla, Querétaro y Tlaxcala, que entre 1993 y 2008 han fortalecido su crecimiento en la producción. Esto es importante porque supone actividades de mayor valor agregado, con lo que las posibilidades de impactar en la generación de empleos son mayores. Destacan sobre todo los casos de Tlaxcala, que entre los años 1993-2008 ha crecido en promedio anual el 8.2\%, y del Distrito Federal e Hidalgo, que registran caídas importantes en su actividad económica (tabla 2).

Finalmente, la División IX. Otras industrias manufactureras registra crecimientos importantes en los dos periodos. Particularmente Puebla se ha convertido en la entidad en la que esta división de actividad se ha consolidado por sus niveles de la actividad económica (del 21.7\% para 1993-2008), lo que significa efectos importantes en la generación de empleos.

De acuerdo con estos datos, en general la región Centro se encuentra en un proceso de crecimiento de la producción manufacturera similar al que reporta Sánchez (2011) en el sentido de que la región paulatinamente ha dejado de ser el núcleo industrial del país, aunque hay divisiones de actividad que han impulsado el crecimiento de la manufactura en algunas de las entidades federativas, entre ellas Puebla, Querétaro y Tlaxcala. En estas condiciones, los efectos en los niveles de empleos generados son evidentes, sobre todo porque, de acuerdo con los argumentos keynesianos, existe una correlación muy importante entre actividad económica y empleo, que se explica por el peso de la demanda efectiva.

De esta forma, los datos de la tabla 2 evidencian esta relación y se identifican las siguientes regularidades: a) aun cuando en algunas divisiones de actividad se reporta una desaceleración en el crecimiento del VACBR, las magnitudes del crecimiento promedio del empleo son mayores, sobre todo en las divisiones I, II, III, V y VI; b) las divisiones que integran las ramas más tecnificadas, con mayores proceso de innovación y altamente exportadoras, como la división VIII, presentan una proporción menor entre crecimiento de la actividad económica y crecimiento del empleo, y c) estas relaciones permiten suponer que la elasticidad ingreso del empleo de los sectores vinculados al 
sector externo, como la división VIII, es menor que los que responden más a factores de demanda interna.

El acercamiento con la información estadística nos aproxima al análisis de lo que está ocurriendo con el crecimiento de la actividad económica y el empleo en las divisiones de actividad de la manufactura para la región Centro de México. El punto es importante, porque supone que esta tendencia de crecimiento de la producción, analizada desde la región Centro, puede aportar en la explicación del lento crecimiento de México y los problemas en la generación de empleos, sobre todo en el sector manufacturero, que, como se ha mencionado, es un sector que se ha desacelerado de manera importante con sus consecuencias en la generación de empleos formales.

A partir de este diagnóstico, en el siguiente apartado se estima, con datos de panel, una función de empleo para cada una de las divisiones de actividad de la manufactura con el propósito de identificar elementos que explican la evolución del empleo en la región Centro.

\section{Empleo y actividad económica. La evidencia empírica para la región Centro de México}

\section{Los argumentos teóricos de la demanda de empleo}

Habitualmente los estudios del empleo parten de explicar la conducta del mercado de trabajo a partir de funciones de oferta y demanda de empleo. En estos casos, el argumento teórico se concentra principalmente en elementos de carácter neoclásico o keynesiano. Para efectos de este trabajo se parte de argumentos keynesianos, específicamente la vertiente de la Nueva Economía Keynesiana (NEK), que supone que el nivel de empleo depende de la demanda efectiva y que el desempleo se puede explicar por la existencia de salarios de eficiencia superiores a los de equilibrio. El hecho de que el empleo depende de la demanda efectiva se explica por los planteamientos de Keynes en el sentido de que cuando una empresa satisface la demanda de su producto, emplea exactamente la cantidad de trabajo necesaria para producir la cantidad demandada. Si se necesita más trabajo para producir una cantidad mayor, las empresas deben emplear más trabajo cuando la demanda de producción es más alta (Abel y Bernanke, 2004), de ahí que se considere una relación positiva entre producción y empleo.

En esta idea, la NEK ha intentado explicar el desempleo a partir de la existencia de un salario real que equilibra el mercado de trabajo y que es esencialmente rígido. Mientras que el modelo neoclásico postulaba la dependencia del salario del nivel de productividad, algunos autores de la NEK invierten los términos de la relación y plantean la posibilidad de que sea la productividad la que dependa positivamente del salario. Su hipótesis central es que, aunque el pago de un salario más elevado genera costes mayores para la empresa, proporciona también más beneficios por su repercusión positiva sobre el esfuerzo de los trabajadores y, en última instancia, sobre la productividad. Los salarios de eficiencia serían las cantidades que las empresas pagarían por encima del valor del salario de equilibrio del mercado para evitar caídas en la productividad (Malcomson, 1981; Gordon, 1990).

Según Mankiw y Romer (1991), la existencia de este tipo de salarios puede obedecer, básicamente, a tres razones: a) a que el salario elevado puede contribuir a aumentar el esfuerzo de los trabajadores y, por lo tanto, repercutirá positivamente sobre su productividad; b) un salario elevado también puede contribuir a mejorar las capacidades de los trabajadores; así, si se supone que el salario de los trabajadores cualificados es mayor y la empresa decide pagar salarios por encima del valor de equilibrio del mercado, se atraerá hacia la empresa a los trabajadores más capacitados y, por lo tanto, aumentará la productividad media de sus trabajadores, y c) un salario 
más elevado puede estimular un sentimiento de lealtad en los trabajadores e inducir un mayor esfuerzo.

En esta discusión se considera importante retomar en el presente trabajo los argumentos de la NEK para tratar de simplificar el análisis del empleo a partir de destacar la relación entre el producto — vía demanda efectiva—y el empleo, y la del salario real — bajo la hipótesis del salario de eficiencia- y el empleo. El análisis se complementa con la inclusión de un índice de diversificación económica que representa una medida empírica de las economías de aglomeración para analizar la estructura económica local. En este caso, la variable de diversificación permite medir el tipo de estructura industrial a partir de evaluar si está diversificada o concentrada (véase Sobrino, 2003) y, en consecuencia, los efectos que puede tener en la generación de empleos. Se espera una correlación positiva entre la diversificación económica y el empleo; a mayor diversificación mayor empleo, sobre todo por la heterogeneidad en la calificación de la mano de obra de las regiones.

\section{La evidencia empírica}

\section{La especificación del panel}

Se integraron nueve paneles, uno para cada gran división de actividad de la industria manufacturera, según se indica en el pie de la tabla 2. Son paneles balanceados con $n=7, T=6$ y $N=42$; es decir, consideran a las 7 entidades federativas que integran la región Centro de México, con cortes transversales de seis periodos que corresponden a la información de los Censos económicos del INEGI (INEGI, 1986, 1989, 1994a, 1999, 2004, 2009), con 42 observaciones.

Se trabajó con las siguientes variables para cada una de las nueve divisiones de actividad de la industria manufacturera: personal ocupado, remuneraciones totales al personal ocupado, valor agregado censal bruto, productividad del trabajo, y se construyó un índice de diversificación económica, como se indica más adelante. En los censos de 1986, 1989 y 1994 el INEGI reportó la información estadística del sector manufacturero a nivel de nueve grandes divisiones; sin embargo, en los censos de 1999, 2004 y 2009 la información del sector manufacturero se encuentra desagregada en veintiún subsectores, por lo que fue necesario agrupar los subsectores para homogeneizar la información a nivel de las nueve grandes divisiones, como previamente se registraba.

La especificación general de un modelo de regresión lineal con datos de panel es la siguiente (Hsiao, 2003):

$$
\begin{aligned}
& Y_{i t}=\alpha+\beta_{i t}+u_{i t} \\
& i=1, \ldots N ; t=1, \ldots T
\end{aligned}
$$

Donde $i$ se refiere al individuo o a la unidad de estudio (corte transversal), $t$ a la dimensión en el tiempo, $\alpha$ es un escalar, $\beta$ es un vector de $K$ parámetros, $X_{i t}$ es la i-ésima observación al momento $t$ para las $K$ variables explicativas y $u_{i t}$ es el término de error.

En este caso, la muestra total de las observaciones en el modelo vendría dada por $N \times T$, donde $N$ es el número de unidades de estudio individual y $T$ el periodo de tiempo.

Los modelos de panel se pueden interpretar a través de sus componentes de errores. El término de error $u_{i t}$ incluido en (1) puede descomponerse de la siguiente manera:

$$
u_{i t}=\mu_{i}+\delta_{t}+e_{i t}
$$


Donde $\mu_{i}$ denota una variable no observable que se mantiene constante a través del tiempo para cada observación (efecto individual no observable), $\delta_{t}$ representa los efectos no cuantificables que varían en el tiempo pero no entre las unidades de estudio y $e_{i t}$ se refiere al término de error. La mayoría de las aplicaciones con datos de panel utilizan el modelo de componente de error en una dirección: $u_{i t}=\mu_{i}+e_{i t}$, para el cual $\delta_{t}=0^{2}$.

A partir de los distintos supuestos sobre los efectos específicos $\mu_{i}$, pueden presentarse tres posibilidades: a) cuando se considera que $\mu_{i}=0$, es decir, que no existe heterogeneidad no observable entre los individuos (por lo que se emplea la regresión agrupada); b) cuando se supone a $\mu_{i}$ como un efecto fijo y distinto para cada individuo, de modo que el modelo lineal es el mismo para todos los individuos pero la ordenada al origen es específica para cada uno de ellos; consecuentemente, en este caso, la heterogeneidad no observable se incorpora a la constante del modelo, y c) cuando se trata a $\mu_{i}$ como una variable aleatoria no observable que varía entre individuos pero no en el tiempo. En este caso, las diferencias no observables se incorporan al término de error.

Estas variantes acerca de la heterogeneidad no observable dan lugar a dos tipos de modelos: el modelo de efectos fijos y el modelo de efectos aleatorios (Montero, 2007; Wooldridge, 2002).

a. El modelo de efectos fijos:

$$
Y_{i t}=\alpha+X_{i t}^{\prime} \beta+\mu_{i}+e_{i t} \text { o bien } Y_{i t}=\alpha_{i}+X_{i t}^{\prime} \beta+e_{i t} ; \alpha_{i}=\alpha+\mu_{i}
$$

supone que el error $u_{i t}$ expresado en (1) puede descomponerse en una parte puramente aleatoria $e_{i t}$ y otra fija constante y diferente para cada individuo $\mu_{i}$ (considerada como un parámetro a estimar para cada observación), lo cual es equivalente a realizar una regresión general y dar a cada individuo un punto de origen (ordenadas) distinto, incorporando así la heterogeneidad a la constante del modelo $\alpha_{i}=\alpha+\mu_{i}$ De esta forma, en el modelo de efectos fijos los $u_{i}$ son tratados como un conjunto de $n$ coeficientes adicionales que se pueden estimar junto con los $\beta_{s}$. Asimismo, el modelo de efectos fijos asume que el efecto individual está correlacionado con los demás regresores, es decir, cov $\left(X_{i t}, \mu_{i}\right) \neq 0$ (Montero, 2007; Wooldridge, 2002).

b. El modelo de efectos aleatorios:

$$
Y_{i t}=\alpha+X_{i t}^{\prime} \beta+\mu_{i}+e_{i t} \quad \text { obien } \quad Y_{i t}=\alpha+X_{i t}^{\prime} \beta+u_{i t}, u_{i t}=\mu_{i}+e_{i t}
$$

tiene la misma especificación que el de efectos fijos, solo que $\mu_{i}$, en lugar de ser un valor fijo para cada individuo y constante a lo largo del tiempo, es una variable aleatoria. Como en el modelo de efectos aleatorios se supone que $\mu_{i}$ es una variable aleatoria inobservable independiente de $X_{i t}$, esta pasa a formar parte de un término de perturbación compuesto $u_{i}=\mu_{i}+e_{i t}$; incorporando así la heterogeneidad no observable al término de error en lugar de la constante como en el caso de efectos fijos (Arellano y Bover, 1990).

Así, a partir de la ecuación (1) se puede estimar una función de empleo para cada una de las nueve grandes divisiones de actividad de la manufactura para las entidades federativas que integran la región Centro de México en términos de un modelo general de regresión lineal con datos de panel.

De esta forma, se define una función de empleo en los siguientes términos:

$$
l_{i t}=\alpha_{i}+\alpha_{1} y_{i t}+I R_{i t}+I P_{i t}+I D E_{i t}+v_{i t}
$$

Donde $l_{i t}$ es la población ocupada para cada división de actividad de la manufactura, desde la división I a la IX; $y_{i t}$ es el valor agregado censal bruto real manufacturero, por división de actividad;

\footnotetext{
${ }^{2}$ Para un mayor detalle puede consultarse Baltagi (2005, cap. 3).
} 
$I R_{i t}$ es un índice de remuneraciones reales manufactureras ${ }^{3} ; I P_{i t}$ un índice de productividad laboral ${ }^{4}$, como variable de eficiencia de cada una de las actividades de la manufactura, y se asume una correlación negativa por el efecto desplazamiento del trabajo (a mayor productividad laboral, menor demanda de trabajo); $I D E_{i t}$ es el índice de diversificación económica, en los términos definidos en el apartado «Los argumentos teóricos de la demanda de empleo» ${ }^{5}$; finalmente, $v_{i t}$ son los errores.

\section{Estimación y discusión de resultados}

La metodología más usada para la estimación de los modelos con datos de panel consiste en establecer si cumple con los supuestos sobre los efectos individuales y de tiempo (fijo o aleatorios), junto con los supuestos econométricos básicos. De ahí que, cuando se trabaja con datos de panel, es un punto central decidir si se estima por efectos fijos o con efectos aleatorios. Entre las pruebas de diagnóstico, para este propósito se encuentra la prueba de Hausman (Toledo, 2012), cuya prueba estadística permite discriminar entre los modelos de efectos aleatorios y los de efectos fijos.

La idea es utilizar las estimaciones de efectos fijos, a menos que la prueba de Hausman ${ }^{6}$ lo rechace (Wooldridge, 2015). En el caso que nos ocupa se sigue la siguiente estrategia, recomendada por Mendoza-González (2014, p. 50): a) evaluar si la especificación de un modelo de datos agrupados (pool) es consistente; para ello se compara con el modelo de efectos fijos; b) si el modelo de efectos fijos es mejor que el de datos agrupados; entonces se evalúa si el modelo de efectos aleatorios es consistente, y c) con el modelo con constantes individuales elegido se analizan las implicaciones analíticas.

En principio se estimó la ecuación (4) para cada una de las grandes divisiones de la manufactura, de la I a la IX, con la técnica de datos agrupados, de efectos fijos y de efectos aleatorios. En sentido estricto, se compararon los modelos de efectos individuales (fijos y aleatorios) con relación al

\footnotetext{
${ }^{3}$ Se construyó un índice salarial relativo a partir de las remuneraciones totales, que incluye sueldos y salarios. De esta forma, $I R_{i t}=\left[\left(w_{i r} / w_{r}\right) /\left(w_{i n} / w_{n}\right)\right]$, donde $w_{i r}$ son las remuneraciones por división de la manufactura y entidad federativa, $w_{r}$ son las remuneraciones para el total de las divisiones de la industria manufacturera en la entidad federativa $r, w_{i n}$ es una medida por división de la manufactura a escala nacional, y $w_{n}$ es la misma variable para el conjunto de las divisiones en el ámbito nacional. Si el valor del índice es menor a 1 se considera una región poco especializada, por lo que las remuneraciones son menores que al promedio nacional de la manufactura, y si es mayor a 1 se considera que las remuneraciones del sector de actividad son competitivas con relación al promedio de las remuneraciones de la manufactura nacional.

${ }^{4}$ Se construyó un índice de productividad relativa de la siguiente forma: $I P_{i r}=\left[\left(y_{i r} / l_{i r}\right) /\left(y_{i n} / l_{n}\right)\right]$, donde el numerador expresa valor agregado por trabajador en una determinada división de actividad $i$ por entidad federativa $r$ y el denominador el valor agregado por trabajador en una determinada división de actividad $i$ a escala nacional $n$. Valores menores a 1 refieren a niveles de productividad de la división de actividad de la entidad federativa menores a los estándares nacionales, y valores mayores a 1 que es más productiva con relación a los estándares nacionales (Sobrino, 2003).

${ }^{5}$ Formalmente se expresa como sigue: $I D E=\left(\frac{n}{n-1}\right) \sum\left[\left(\frac{p_{i}}{p_{t}}\right)-\left(\frac{1}{n}\right)\right]^{2}$, donde $n$ es el número de divisiones de actividad, $p_{i}$ es la producción de la división de actividad $i, \mathrm{y} t$ es la producción total local. El IDE es un valor positivo entre 0 y 1: menor a 1 indica una mayor diversificación, y cuando el índice se acerca a 1 , se considera concentrada (Sobrino, 2003).

${ }^{6}$ La hipótesis que sigue la prueba de Hausman para analizar la consistencia del modelo panel con efectos aleatorios se resume en lo siguiente (Mendoza-González, 2014): $H_{0}$, el estimador de efectos aleatorios (EA) es consistente con relación al estimador de efectos fijos (EF); $H_{l}$, el estimador EF es consistente con relación al estimador EA. El estadístico para probar se define como: $\chi^{2}(k): H=\left[\beta_{E F}-\beta_{E A}\right]^{T}\left[\operatorname{Cov}\left(\beta_{E F}\right) \operatorname{Cov}\left(\beta_{E A}\right)\right]^{-1}\left[\beta_{E F}-\beta_{E A}\right]$

Donde $\beta$ es el vector de coeficientes compuesto con los parámetros del modelo, Cov es la matriz de varianza-covarianza y $k$ es el número de coeficientes.
} 
modelo de datos agrupados (pool), por lo que primero se comparó el modelo de efectos fijos con el modelo de datos agrupados para evaluar la eficiencia del modelo de efectos fijos. Para ello, la prueba de datos agrupados utiliza una prueba de restricción de parámetros entre los dos modelos y se analizan las hipótesis: $\mathrm{H}_{0}: \forall \mu_{\mathrm{i}}=0 ; \mathrm{H}_{1}: \mu_{1} \neq 0, \ldots, \mu_{\mathrm{i}} \neq 0$ (véase Mendoza-González, 2014). Si la hipótesis nula $\mathrm{H}_{0}$ no se puede rechazar, se opta por el modelo de datos agrupados; en caso contrario, se elige el de efectos fijos.

Para analizar las hipótesis se utiliza un estadístico $\chi^{2}(k)$ con los $k$ grados de libertad definidos por la cantidad de efectos individuales; a esta prueba se la conoce como pool (prueba de datos agrupados). En caso de que el modelo de efectos fijos sea eficiente con relación al modelo pool, se puede analizar si el modelo de efectos aleatorios es eficiente con relación al modelo de efectos fijos. Para ello se utiliza la prueba de Hausman (Mendoza-González, 2014).

De acuerdo con los resultados de las pruebas de datos agrupados (pool test) y la prueba de Hausman, se concluyó que para las divisiones II, III y IX el mejor modelo es el de datos agrupados, por lo que se puede concluir que es consistente con el de efectos fijos; para las divisiones I, IV, V, VI, VII y VIII el mejor modelo es el de efectos fijos (véanse resultados de la prueba en la tabla 3).

De la estimación se identifican algunas regularidades importantes, sobre todo las relacionadas con la correlación entre el valor agregado censal bruto y el empleo. A partir de los resultados de la estimación, específicamente del resultado de los coeficientes de $y_{i t}$, se agruparon las divisiones de actividad de la manufactura en tres: a) las que reportan una alta elasticidad ingreso del empleo; b) las de elasticidad media, y c) las de baja elasticidad (tabla 3$)^{7}$.

Entre las primeras se encuentran las divisiones I. Productos alimenticios, bebidas y tabaco; II. Textiles, prendas de vestir e industria del cuero; III. Industria de la madera y productos de madera, y IX. Otras industrias manufactureras, cuyos coeficientes del valor agregado censal bruto, $y$, son de $0.716,1.035,0.781$ y 0.94 . Los resultados indican que cuando la actividad económica en estas divisiones de actividad crece en $1.0 \%$, el empleo lo hace en $0.799,1.035,0.781$ y $0.94 \%$, respectivamente, lo que estaría indicando que en la región Centro del país estas divisiones son altamente generadoras de empleos.

Las divisiones que registran elasticidades medias son: IV. Papel, productos de papel, imprentas y editoriales; V. Sustancias químicas; derivados del petróleo; productos de caucho y plásticos, y VIII. Productos metálicos, maquinaria y equipo, con coeficientes de $0.424,0.418$ y 0.565 , mientras que las que presentan elasticidades relativamente bajas son las divisiones VI. Productos de minerales no metálicos, exceptuando derivados del petróleo y carbón y VII. Industrias metálicas básicas, con coeficientes de 0.051 y 0.27 (tabla 3).

Los resultados dejan ver que la producción en la división VI prácticamente ha perdido su capacidad de generar empleo. Quizá esto se debe a que es una división cuya actividad se explica por la producción de productos de minerales no metálicos, exceptuando derivados del petróleo y carbón, que en la región es relativamente escasa.

De acuerdo con los argumentos de la NEK del apartado «Los argumentos teóricos de la demanda de empleo», se esperaría que los resultados de la estimación arrojaran coeficientes con signo negativo en la variable $I R$; sin embargo, este argumento solo es consistente en las divisiones $\mathrm{V}$ y

\footnotetext{
7 Más que identificar a las divisiones de actividad por el tipo de elasticidad de la demanda de empleo (como elástica, inelástica o unitaria, dependiendo de si su valor es mayor, menor o igual a 1), se agruparon por la magnitud del coeficiente a partir de identificar a las divisiones cuya generación de empleo es más o menos sensible a los niveles de crecimiento de la producción.
} 
Tabla 3

Estimación del empleo por gran división de la manufactura región Centro de México, 1985-2008

\begin{tabular}{|c|c|c|c|c|c|c|c|c|c|}
\hline \multicolumn{10}{|c|}{ Variable endógena: población ocupada } \\
\hline & División $\mathrm{I}^{\mathrm{a}}$ & División $\mathrm{II}^{\mathrm{b}}$ & División III ${ }^{\mathrm{b}}$ & División IV $\mathrm{I}^{\mathrm{a}}$ & División $\mathrm{V}^{\mathrm{a}}$ & División $\mathrm{VI}^{\mathrm{a}}$ & División VII $^{\mathrm{a}}$ & División VIII $^{\mathrm{a}}$ & División IX ${ }^{\mathrm{b}}$ \\
\hline constante & & -5.562 & $-1.861(0.00)$ & & & & & & $-3.62(0.00)$ \\
\hline$y$ & $0.716(0.00)$ & $1.035(0.00)$ & $0.781(0.00)$ & $0.424(0.00)$ & $0.418(0.007)$ & $0.051(0.008)$ & $0.27(0.002)$ & $0.565(0.00)$ & $0.94(0.00)$ \\
\hline$I R$ & $0.526(0.003)$ & $0.411(0.00)$ & $1.344(0.00)$ & $0.865(0.00)$ & $-0.007(0.66)$ & $0.416(0.00)$ & $0.149(0.205)$ & $-0.085(0.45)$ & $0.481(0.033)$ \\
\hline$I P$ & $0.554(0.00)$ & $-0.484(0.00)$ & $-0.978(0.009)$ & $-0.239(0.043)$ & $-0.118(0.173)$ & $0.069(0.248)$ & $0.45(0.526)$ & $-0.218(0.00)$ & $-0.75(0.00)$ \\
\hline$I D E$ & $0.076(0.897)$ & $1.596(0.03)$ & $1.68(0.011)$ & $1.563(0.079)$ & $1.232(0.171)$ & $1.248(0.099)$ & $-3.469(0.275)$ & $0.421(0.337)$ & $-0.508(0.494)$ \\
\hline $\mathrm{R} 2$ & 0.803 & 0.912 & 0.956 & 0.689 & 0.28 & 0.56 & 0.384 & 0.769 & 0.964 \\
\hline R2 ajustado & 0.593 & 0.801 & 0.843 & 0.509 & 0.207 & 0.443 & 0.283 & 0.563 & 0.849 \\
\hline F estadístico & $31.703(0.00)$ & $93.352(0.00)$ & $203.517(0.00)$ & $17.197(0.00)$ & $3.022(0.032)$ & $11.613(0.00)$ & $4.831(0.00)$ & $90.062(0.00)$ & $248.753(0.00)$ \\
\hline $\begin{array}{l}\text { Prueba } \\
\text { de datos } \\
\text { agrupados }\end{array}$ & $4.15(0.003)$ & $1.775(0.138)$ & $1.647(0.168)$ & $6.712(0.000)$ & $4.584(0.002)$ & $60.588(0.000)$ & $3.871(0.005)$ & $18.494(0.000)$ & $1.148(0.359)$ \\
\hline $\begin{array}{l}\text { Prueba de } \\
\text { Hausman }\end{array}$ & $3.970(0.410)$ & & & $4.692(0.320)$ & $5.144(0.273)$ & $3.062(0.548)$ & $3.733(0.443)$ & & \\
\hline
\end{tabular}

División I. Productos alimenticios, bebidas y tabaco; División II. Textiles, prendas de vestir e industria del cuero; División III. Industria de la madera y productos de madera; División IV. Papel, productos de papel, imprentas y editoriales; División V. Sustancias químicas; derivados del petróleo; productos de caucho y plásticos; División VI. Productos de minerales no metálicos, exceptuando derivados del petróleo y carbón; División VII. Industrias metálicas básicas; División VIII. Productos metálicos, maquinaria y equipo; División IX. Otras industrias manufactureras.

a Modelo de efectos fijos.

b Modelo de datos agrupados.

Fuente: estimaciones propias con R versión 3.0.1. (R Core Team, 2013). 
VIII, cuyos coeficientes son -0.007 y -0.085 (tabla 3 ). Como se observa son muy bajos, lo que dejaría ver que los salarios ya no son una variable que explica el crecimiento del empleo.

Con relación al índice de productividad $(I P)$, se esperaba una correlación negativa asumiendo que se presenta un fenómeno de desplazamiento de trabajo. Este argumento es válido para las divisiones II, III, IV, V, VIII y IX, cuyos coeficientes del IP son $-0.484,-0.978,-0.641,-0.118$, -0.218 y -0.75 , respectivamente (tabla 3 ). Como se observa, las magnitudes de los coeficientes son diversas, lo que permite argumentar que hay divisiones de actividad en las que se puede estar presentando procesos de innovación que estén favoreciendo la productividad del trabajo con los consecuentes efectos de desplazamiento de mano de obra.

Finalmente, se evidencia una correlación positiva entre $I D E$ y empleo, lo que estaría validando la hipótesis de las economías de aglomeración, en el sentido de que a mayor diversificación mayor empleo, sobre todo por la heterogeneidad en la calificación de la mano de obra que se supone existe en las entidades federativas de la región Centro. Al respecto, los resultados estarían indicando correlaciones importantes para las divisiones III, IV, V y VI (coeficientes de 1.68, 1.563, 1.232 y 1.248 , respectivamente).

\section{Conclusiones}

La evidencia empírica muestra que a nivel nacional la manufactura ha disminuido sus tasas de crecimiento durante al menos las últimas tres décadas, lo que indudablemente ha tenido efectos negativos en la generación de empleo formal. Esta situación se ha transferido a las entidades federativas y a las regiones del país. La región Centro de México no ha sido ajena a esta tendencia de lento crecimiento con escasa generación de empleo: dejó de crecer a las tasas que tuvo hasta antes de la crisis de 1982 y ha mantenido una tendencia similar al comportamiento de la economía mexicana, con una tasa promedio del $2.4 \%$ y con una tasa de crecimiento del empleo negativa, del $-0.1 \%$.

Esta situación sin duda resulta muy preocupante, pues no solo se presenta para el sector manufacturero considerado motor de crecimiento de la economía, sino que también se hace evidente en una de las regiones más importantes del país y que por muchos años ha sido la que mayor aportación tiene al PIB total nacional y al manufacturero, pero también una de las mayores generadoras de empleo formal.

Los efectos han sido diferenciados para las entidades federativas de la región. El Distrito Federal y el Estado de México, aun cuando siguen siendo dos de los estados más representativos a nivel nacional por su aportación al PIB total y al manufacturero, han presentado fuertes disminuciones en las tasas de crecimiento de las actividades industriales. Por otro lado, hay divisiones de actividad que han impulsado el crecimiento de la manufactura en algunas de las entidades federativas, entre ellas Puebla, Querétaro y Tlaxcala.

A partir de los resultados de la estimación se identifican divisiones de la manufactura cuya demanda de empleo es muy sensible al crecimiento de la actividad económica, particularmente las divisiones I. Productos alimenticios, bebidas y tabaco; II. Textiles, prendas de vestir e industria del cuero; III. Industria de la madera y productos de madera, y IX. Otras industrias manufactureras, cuya elasticidad ingreso del empleo es de $0.716,1.035,0.781$ y 0.94 . Por los coeficientes se puede considerar que en la región Centro de México estas divisiones de actividad son altamente generadoras de empleos.

Para el caso de la variable $I R$, los resultados de la estimación solo son consistentes para las divisiones V y VIII, cuyos coeficientes son -0.007 y -0.085 ; sin embargo, los coeficientes 
son muy bajos, lo que permite suponer que los salarios ya no son una variable que explica el crecimiento del empleo.

Con relación al índice de productividad $(I P)$, se identificaron diferentes magnitudes de los coeficientes estimados para las diferentes divisiones de actividad. Se reportan correlaciones negativas entre productividad y empleo para las divisiones II, III, IV, V, VIII y IX, con coeficientes de $-0.484,-0.978,-0.641,-0.118$ y -0.218 y -0.75 , respectivamente.

Se evidencia una correlación positiva entre $I D E$ y empleo, para las divisiones III, IV, V y VI (coeficientes de 1.68, 1.56, 1.23 y 1.24, respectivamente). Sin embargo, solo para el caso de la división III el coeficiente es estadísticamente significativo, lo que estaría validando el supuesto de que a mayor diversificación mayor empleo, sobre todo por la heterogeneidad en la calificación de la mano de obra que se supone existe en las entidades federativas de la región Centro.

Finalmente, y a partir de la evidencia que aquí se presenta, es importante reconsiderar el papel que desempeña la industria manufacturera como impulso al crecimiento de la actividad económica, tanto en la región Centro de México como en el resto de las regiones del país, sobre todo porque es un sector que puede retomar el papel de motor del crecimiento de la economía mexicana, como la ha argumentado la ONUDI (2013): «durante los últimos 40 años, los grandes ganadores en materia de empleo en la industria manufacturera han sido los países en vías de industrialización, lo que confirma la importancia de esta industria como fuente de empleo a nivel mundial».

\section{Referencias}

Abel, A. B. y Bernanke, B. S. (2004). Macroeconomía (4. ${ }^{\mathrm{a}}$ ed.). Madrid: Pearson-Addison Wesley.

Alcaraz, C. y García, R. (2006). Cambios en la composición del empleo y evolución de la productividad del trabajo en el sector formal de la economía mexicana: 2000-2005. Documentos de Investigación No. 2006-3. México: Banco de México.

Arellano, M. y Bover, O. (1990). La Econometría de datos de panel. Investigaciones Económicas (segunda época), XIV (1), 3-45.

Arriaga, R., Leyva, E. y Estrada, J. L. (2005). Perfil y estructura industrial de Guanajuato y Querétaro: un análisis de la producción, el empleo y los salarios. Análisis Económico, 20(44), 135-189. http://www.redalyc. org/articulo.oa? id=41304406

Baltagi, B. (2005). Econometric Analysis of Panel Data (3rd ed.). Chichester, UK: John Wiley \& Sons.

Calderón, C. y Martínez, G. (2005). La ley de Verdoom y la industria manufacturera regional en México en la era del TLCAN. Frontera Norte, 17(34), 103-137. http://www.redalyc.org/articulo.oa?id=13603404

Calderón, C. y Sánchez, I. (2012). Crecimiento económico y política industrial en México. Problemas del desarrollo. Revista Latinoamericana de Economía, 43(170), 125-154. http://www.redalyc.org/articulo.oa?id=11823063006

Chávez, F. y Zepeda, E. (1996). El sector servicios: desarrollo regional y empleo. México: Universidad Autónoma de Coahuila-Fundación Friederich Ebert.

De León, A. (2013). El desempeño productivo regional de las manufacturas mexicanas. Un análisis en las entidades federativas (1970-2008). Jalisco: Universidad de Guadalajara.

De León, A. (2002). El Tratado de Libre Comercio en América del Norte y el crecimiento económico en las manufacturas mexicanas: una perspectiva regional. México: Universidad de Guadalajara, división de Gestión Empresarial.

Dussel Peters, E. (1997). Economía de la polarización. Teoría y evolución del cambio estructural de las manufacturas mexicanas (1988-1996). México: JUS-UNAM.

Dussel Peters, E. (2003). Características de las actividades generadoras de empleo en la economía mexicana (1988-2000). Investigación Económica, 62(243), 123-154. http://www.redalyc.org/articulo.oa?id=60124304

Dussel Peters, E. y Cárdenas, H. (2007). México y China en la cadena hilo-textil-confección en el mercado de Estados Unidos. Comercio Exterior, 57(7), 530-545.

Dussel Peters, E. y Ortiz, S. (2013). Tendencias macroeconómicas. Monitor de la Manufactura Mexicana, 9(10), 13-29. 
Dussel Peters, E. y Ortiz, S. (2012). Tendencias macroeconómicas. Monitor de la Manufactura Mexicana, 8(9), $11-24$.

Escobar-Méndez, A. (2011). Determinantes del empleo en la industria manufacturera en México. Papeles de Población, 17(67), 251-276. http://www.redalyc.org/articulo.oa?id=11219005008

Flores, J. y Capdevielle, M. (2003). Especialización productiva y comercial de las manufacturas mexicanas: determinantes y problemáticas. Integración y desarrollo regional. México, DF: UAM-X, CSH, Departamento de Producción Económica.

Fragoso, E. C. (2003). Apertura comercial y productividad en la industria manufacturera mexicana. Economía Mexicana, 12(1), 5-38. http://www.redalyc.org/articulo.oa?id=32312101

Fujii, G. y Cervantes, R. (2008). Apertura comercial y empleo en México, 1988-2004. Querétaro: Ponencia VI Congreso Nacional de la Asociación Mexicana de Estudios del Trabajo.

Garduño, S. O. (2009). Ciclos económicos manufactureros en México. Territorio y Economía, 27, 15-25.

Gordon, R. (1990). What is new Keynesian economics? Journal of Economic Literature, 28(3), $1115-1171$. http://www.jstor.org/stable/2727103

Guerrero de Lizardi, C. (2012). La manufactura mexicana, diagnóstico de su estructura y programas locales de apoyo: prácticas, logros y pendientes hacia una política industrial nacional. Chile: Comisión Económica para América Latina y el Caribe.

Hanson, G. (1994). Regional Adjustment to Trade Liberalization, Working Paper No. 4713. Cambridge: National Bureau of Economic Research.

Hsiao, C. (2003). Analysis of Panel Data (2nd ed.). Cambridge, Reino Unido: Cambridge University Press.

INEGI (1970). IX Censo General de Población. México: Instituto Nacional de Estadística y Geografía.

INEGI (1980). X Censo de General de Población y Vivienda. México: Instituto Nacional de Estadística y Geografía.

INEGI (1986). Censo Económico 1985. México: Instituto Nacional de Estadística y Geografía.

INEGI (1989). Censo Económico 1988. México: Instituto Nacional de Estadística y Geografía.

INEGI (1990). XI Censo General de Población y Vivienda. México: Instituto Nacional de Estadística y Geografía.

INEGI (1994). Censo Económico 1993. México: Instituto Nacional de Estadística y Geografía.

INEGI (1994-2012). Encuesta Industrial Mensual. México: Instituto Nacional de Estadística y Geografía.

INEGI (1999). Censo Económico 1998. México: Instituto Nacional de Estadística y Geografía.

INEGI (2000). XII Censo General de Población y Vivienda. México: Instituto Nacional de Estadística y Geografía.

INEGI (2004). Censo Económico 2003. México: Instituto Nacional de Estadística y Geografía.

INEGI (2005). Encuesta Nacional de Ocupación y Empleo (ENOE). México: Instituto Nacional de Estadística y Geografía.

INEGI (2009). Censo Económico 2008. México: Instituto Nacional de Estadística y Geografía.

INEGI (2010). Censo de Población y Vivienda. México: Instituto Nacional de Estadística y Geografía.

INEGI (2012). Sistema de Cuentas Nacionales. México: Instituto Nacional de Estadística y Geografía.

INEGI (2014a). Sistema de Cuentas Nacionales. México: Instituto Nacional de Estadística y Geografía.

INEGI (2014b). Encuesta Nacional de Ocupación y Empleo (ENOE). México: Instituto Nacional de Estadística y Geografía.

INEGI (2014c). México en cifras. Información nacional por entidad federativa y municipios. México: Instituto Nacional de Estadística y Geografía.

Livas, R. y Krugman, P. (1992). Trade Policy and the Third World Metropolis, Working Paper No. 4238. Cambridge: National Bureau of Economic Research.

Malcomson, J. (1981). Unemployment and the efficiency wage hypothesis. The Economic Journal, 91(364), 848-866. http://dx.doi.org/10.2307/2232496

Mankiw, G. y Romer, D. (1991). New Keynesian Economics. Cambridge, Massachusetts: The MIT Press.

Mariña, A. (2005). Balance y perspectivas de la industria manufacturera mexicana tras veinte años de reestructuración neoliberal: Integración subordinada a Estados Unidos, desindustrialización y precarización del empleo. México: Universidad Autónoma Metropolitana-Azcapotzalco.

Martínez, M., Barajas, M. y Ruiz, W. (2012). Crecimiento del empleo manufacturero y externalidades: México y Marruecos en las regiones fronterizas. Análisis Económico, 27(65), 57-88.

Mendoza-González, M. Á. (2014). Inflación y desempleo en las ciudades mexicanas: una evaluación con modelos panel. En L. Quintana y R. Andrés-Rosales (Eds.), Técnicas modernas de análisis regional (pp. 45-62). México: FES-Acatlán, UNAM-Plaza y Valdés.

Montero, R. (2007). Efectos fijos o variables: test de especificación. Documento de trabajo en Economía Aplicada. España: Universidad de Granada.

ONUDI. (2013). Informe sobre el Desarrollo Industrial 2013. La creación sostenida de empleo: el rol de la industria manufacturera y el cambio estructural. Organización de las Naciones Unidas para el Desarrollo Industrial. 
Quintana, L., Andrés-Rosales, R. y Namkwon, M. (2013). Crecimiento y desarrollo regional de México y Corea del Sur: un análisis comparativo de las leyes de Kaldor. Investigación Económica, 72(284), 83-110. http://www.redalyc.org/articulo.oa?id=60128351004

R Core Team R. (2013). R: A language and environment for statistical computing. Vienna, Austria: R Foundation for Statistical Computing. URL: http://www.R-project.org/

Sánchez, I. (2011). Estancamiento económico en México, manufacturas y rendimientos crecientes: un enfoque kaldoriano. Investigación Económica, 70(277), 87-126. http://www.redalyc.org/articulo.oa?id=60120242005

Sánchez, I. (2012). Ralentización del crecimiento y manufacturas en México. Nóesis, Revista de Ciencias Sociales y Humanidades, 21(41), 137-170. http://doi.org/10.20983/noesis.2012.1.6

Sobrino, J. (2003). Competitividad de las ciudades en México. México: El Colegio de México.

Toledo, W. (2012). Una introducción a la econometría con datos de panel. Ensayos y monografías, Núm. 152. Universidad de Puerto Rico. URL: http://economia.uprrp.edu/Ensayo\%20152.pdf

Wooldridge, J. M. (2002). Econometric Analysis of Cross Section and Panel Data. Cambridge: The MIT Press.

Wooldridge, J. M. (2015). Introducción a la econometría (5. a ed.). México: Cengage Learning editores. 